\title{
Identification of alleles of carotenoid pathway genes important for zeaxanthin accumulation in potato tubers
}

\author{
Anne-Marie A. Wolters • Jan G. A. M. L. Uitdewilligen • \\ Bjorn A. Kloosterman • Ronald C. B. Hutten • \\ Richard G. F. Visser • Herman J. van Eck
}

Received: 14 January 2010/ Accepted: 30 April 2010/Published online: 19 May 2010

(C) The Author(s) 2010. This article is published with open access at Springerlink.com

\begin{abstract}
We have investigated the genetics and molecular biology of orange flesh colour in potato (Solanum tuberosum L.). To this end the natural diversity in three genes of the carotenoid pathway was assessed by SNP analyses. Association analysis was performed between SNP haplotypes and flesh colour phenotypes in diploid and tetraploid potato genotypes. We observed that among eleven beta-carotene hydroxylase 2 (Chy2) alleles only one dominant allele has a major effect, changing white into yellow flesh colour. In contrast, none of the lycopene epsilon cyclase (Lcye) alleles seemed to have a large effect on flesh colour. Analysis of zeaxanthin epoxidase (Zep) alleles showed that all (diploid) genotypes with orange tuber flesh were homozygous for one specific Zep allele. This Zep allele showed a reduced level of expression. The complete genomic sequence of the recessive Zep allele, including the promoter, was determined, and compared with the sequence of other Zep alleles. The most striking difference was the presence of a non-LTR retrotransposon sequence in intron 1 of the recessive Zep allele, which was absent in all other Zep alleles investigated. We hypothesise that the presence of this large sequence in intron 1 caused
\end{abstract}

Electronic supplementary material The online version of this article (doi:10.1007/s11103-010-9647-y) contains supplementary material, which is available to authorized users.

A.-M. A. Wolters $(\varangle)$ · J. G. A. M. L. Uitdewilligen

B. A. Kloosterman - R. C. B. Hutten .

R. G. F. Visser - H. J. van Eck

Laboratory of Plant Breeding, Wageningen University,

P.O. Box 386, 6700 AJ Wageningen, The Netherlands

e-mail: Anne-marie.Wolters@wur.nl

R. G. F. Visser · H. J. van Eck

Center for BioSystems Genomics (CBSG),

6700 AB Wageningen, The Netherlands the lower expression level, resulting in reduced Zep activity and accumulation of zeaxanthin. Only genotypes combining presence of the dominant Chy 2 allele with homozygosity for the recessive Zep allele produced orange-fleshed tubers that accumulated large amounts of zeaxanthin.

Keywords Solanum tuberosum - SNP analysis . Allele mining · Orange flesh · Carotenoids . Zeaxanthin epoxidase

$\begin{array}{ll}\text { Abbreviations } \\ \text { Chy2 } & \text { Beta-carotene hydroxylase } 2 \\ \text { Lcye } & \text { lycopene epsilon cyclase } \\ \text { Zep } & \text { Zeaxanthin epoxidase } \\ \text { AMD } & \text { Age-related macular degeneration } \\ \text { eQTL } & \text { Expression quantitative trait locus } \\ \text { POCI } & \text { Potato oligo chip initiative } \\ \text { SNP } & \text { Single nucleotide polymorphism } \\ \text { CAPS } & \text { Cleaved amplified polymorphic sequence } \\ \text { BAC } & \text { Bacterial artificial chromosome } \\ \text { PGSC } & \text { Potato genome sequencing consortium } \\ \text { SIFT } & \text { Sorting intolerant from tolerant } \\ \text { PolyPhen } & \text { Polymorphism phenotyping } \\ \text { qRT-PCR } & \text { Quantitative real-time polymerase chain } \\ & \text { reaction } \\ \text { LTR } & \text { Long terminal repeat }\end{array}$

Introduction

Flesh colour in most tetraploid potato cultivars ranges from white via cream and yellow to dark yellow. This yellow 
colour is caused by the presence of specific carotenoids. A small number of cultivars have red or blue/purple flesh, caused by the presence of anthocyanins.

The main carotenoids present in cultivated potato are lutein, violaxanthin, zeaxanthin and antheraxanthin (Breithaupt and Bamedi 2002; Brown et al. 1993; Iwanzik et al. 1983; Nesterenko and Sink 2003). Beta-carotene, the precursor of vitamin A, is almost absent in S. tuberosum genotypes or closely related Solanum species (Breithaupt and Bamedi 2002). Carotenoids are recognised as important health promoting ingredients of the human diet. Some have antioxidant properties, and are supposedly beneficial in preventing cancer, cardiac disease, and eye diseases (Krinsky et al. 2004). Lutein and zeaxanthin are thought to be important in the human diet to prevent age-related macular degeneration (AMD; Moeller et al. 2006; Seddon et al. 1994; Snodderly 1995). Lutein and zeaxanthin are components of the macula lutea in the human eye (Handelman et al. 1988), protecting the retina against damaging irradiation, but they have to be replenished constantly. As humans can not produce lutein and zeaxanthin themselves they have to be consumed by eating carotenoid-rich plant products. Lutein is present in high amounts in dark green leafy vegetables such as spinach and kale. Zeaxanthin, however, is less abundant in most vegetables (Sommerburg et al. 1998).

In tetraploid potato lutein is present in relatively large amounts, whereas zeaxanthin is present in lower amounts (Breithaupt and Bamedi 2002; Nesterenko and Sink 2003). However, some Solanum species closely related to S. tuberosum have high zeaxanthin content (Andre et al. 2007). These are known as 'Papa Amarilla' because of their deep yellow or orange-fleshed tubers. These landraces grown by indigenous farmers in the Andean region belong to the diploid species S. stenotomum, S. goniocalyx and S. phureja (Brown et al. 2007; Burgos et al. 2009). Brown et al. (2007) and Brown (2008) observed a relationship between ploidy level and total carotenoid content in 38 native South American cultivars. Significantly higher mean levels of total carotenoids were observed in diploid cultivars compared with tetraploid cultivars. Morris et al. (2004) describe a diploid high carotenoid-accumulating S. phureja accession (DB375 $\backslash$, or 'Inca Dawn') that predominantly contains zeaxanthin, but has a lower yield than tetraploid S. tuberosum cultivars (Bradshaw and Ramsay 2005). Kobayashi et al. (2008) bred a diploid potato variety with orange flesh and very high zeaxanthin content. This variety was derived from $S$. phureja. It would be interesting to obtain high-yielding orange-fleshed tetraploid potato cultivars to aid in the recommended daily uptake of zeaxanthin, as potatoes and potato products constitute a considerable part of the human diet in the Western world.
Yellow flesh colour in potato is mainly dependent on the presence of a dominant allele (Fruwirth 1912) at the $Y$ (Yellow) locus. The $Y$ locus has been mapped on chromosome 3 of potato by Bonierbale et al. (1988). The most likely candidate for the gene involved in yellow flesh colour is beta-carotene hydroxylase (abbreviated to Bch or Chy2; Brown et al. 2006). This gene has been mapped at the same position as the $Y$ locus (Thorup et al. 2000).

Until now, the gene(s) responsible for the orange tuber flesh colour in diploid Solanum species are unknown. Brown et al. (1993) observed progeny with orange flesh colour and high levels of zeaxanthin in a hybrid population of S. phureja-S. stenotomum. They suggested that the orange phenotype was caused by a dominant $O r$ allele at or close to the $Y$ locus on chromosome 3 of potato. However, this was not corroborated by later research, as Brown (2008) reported. Lack of transmissibility outside the immediate 'Papa Amarilla' gene pool negated the hypothesis that the expression of Or was consistent with a strong dominant monogenic inheritance. In cauliflower an $\mathrm{Or}$ gene was cloned, responsible for orange-coloured curds (Lopez et al. 2008). This gene was found not to be involved in the carotenoid biosynthesis pathway, but to control chromoplast differentiation, resulting in the sequestering of large amounts of carotenoids.

This paper describes DNA polymorphisms among haplotypes of three candidate genes involved in the carotenoid pathway in monoploid, diploid and tetraploid potato genotypes, and explains the inheritance of yellow and orange potato tuber flesh colour.

\section{Materials and methods}

\section{Plant materials}

For sequence analyses DNA was used from five monoploid potato genotypes: 7322 (H7322 or AM79.7322, originally from G. Wenzel, Institüt für Genetik, Grünbach, Germany, see: De Vries et al. 1987; Hovenkamp-Hermelink et al. 1988), M5 and M38 (851-5 and 851-38, Uijtewaal 1987), M47 and M133 (1022 M-47 and 1022 M-133, Hoogkamp et al. 2000). DNA from 20 monoploid $S$. phureja and S. chacoense clones was obtained from Richard Veilleux (Blacksburg, Virginia, USA, see Lightbourn and Veilleux 2007). DNA was isolated from eleven diploid genotypes: C (USW5337.3, Hanneman and Peloquin 1967), E (77.2102.37, Jacobsen 1980), RH88-025-50 and RH90038-21 (Park et al. 2005), RH89-039-16 and SH83-92-488 (Rouppe van der Voort et al. 1997; Van Os et al. 2006), $87.1024 / 2$ and 87.1029/31 (Jacobsen et al. 1989), G254 (Uijtewaal et al. 1987), R5 (EJ92-6486-19, from cross 87.1024/2 $\times$ EJ91-6104-19) and 413 (transformant of 
interdihaploid $\mathrm{H}^{2} 260$; Binding et al. 1978; De VriesUijtewaal et al. 1989). Three diploid orange-fleshed genotypes were analysed: cultivars 'Papa Pura' and 'Andean Sunrise' (provided by Agrico Research BV), and S. phureja 'Yema de Huevo' (obtained from Enrique Ritter, Vitoria, Spain, see Ritter et al. 2008). Two diploid populations were analysed in which orange-fleshed progeny segregated: the $\mathrm{C} \times \mathrm{E}$ population (Jacobs et al. 1995) and the IvP92-030 population (cross G254 × SUH2293, from Ronald Hutten, Lab. of Plant Breeding, Wageningen University). Furthermore, orange-fleshed diploid genotype IvP01-84-19 from the cross 96-4622-20 $\times$ IvP92-027-9 (Ronald Hutten) was included. Additionally, a set of 225 tetraploid cultivars was used (D'hoop et al. 2008; D'hoop 2009). In this set no genotypes with orange-fleshed tubers were present. Flesh colour of the tetraploids was determined in a field experiment in 2006 (D'hoop 2009). Flesh colour values were on an ordinal scale ranging from 4 (=white) to 9 (=orange) according to the Dutch Catalogue of Potato Varieties (www.nivap.nl).

\section{DNA isolation}

Genomic DNA from the monoploid and diploid genotypes was isolated from leaf tissue according to the CTAB method from Rogers and Bendich (1988). DNA from the tetraploid cultivars was isolated according to Van der Beek et al. (1992).

\section{PCR amplification and sequencing}

Amplicons for sequencing were generated from $50 \mathrm{ng}$ genomic DNA template. PCR amplifications were performed in 50 or $25 \mu \mathrm{l}$ reactions using $1 \mathrm{u}$ of Taq polymerase, $1 \times$ reaction buffer, $200 \mathrm{nM} \mathrm{dNTP}$ and $250 \mathrm{nM}$ of each primer. Standard cycling conditions were: $4 \mathrm{~min}$ initial denaturation at $94^{\circ} \mathrm{C}$, followed by 35 cycles of $30 \mathrm{~s}$ denaturation at $94^{\circ} \mathrm{C}, 30 \mathrm{~s}$ annealing at $55^{\circ} \mathrm{C}$ and $30 \mathrm{~s}$ to $1 \mathrm{~min}$ extension at $72^{\circ} \mathrm{C}$. Reactions were finished by $7 \mathrm{~min}$ incubation at $72^{\circ} \mathrm{C}$. For CAPS marker analysis 30 cycles were used. Most PCRs were performed with SuperTaq Polymerase buffer and enzyme (Applied Biosystems). PCR products were examined for quality on ethidium bromide-stained agarose gels. PCR products were directly sequenced on ABI377 or ABI3700 sequencers at Greenomics (Wageningen University and Research Centre) using the dideoxy chain-termination method and ABI PRISM Reaction Kit. One or both of the amplification primers were used as sequencing primers. For SNP analysis of the Chy 2 gene primers CHY2ex4F (5'-CCATAGACCAAGAGAAGGAC C- $\left.3^{\prime}\right)$ and Beta-R822 (5'-GAAAGTAAGGCACGTTGGCA AT- $3^{\prime}$ ) were used. For SNP analysis of the Lcye gene primers AWLCYe1 (5'-AAAAGATGCAATGCCATTCGAT-3') and AWLCYe2 (5'-GAAATACTCGGGGTACTTGAAC- $3^{\prime}$ ) were used. For SNP analysis of the Zep gene primers AWZEP9 (5'-GTGGTTCTTGAGAATGGACAAC- $\left.3^{\prime}\right)$ and AWZEP10 (5'-CACCAGCTGGTTCATTGTAAAA-3') were used. As CAPS marker for Chy2 the 308-bp CHY2ex4F + Beta-R822 PCR product was cleaved with AluI. The 163-bp fragment was indicative for the presence of Chy 2 allele 3 . As CAPS marker for Lcye the AWLCYe1 + AWLCYe2 PCR product was digested with SsiI, which distinguished allele 2 from alleles 1 and 3. By digesting the AWLCYe1+ AWLCYe2 PCR product with HpyCH4IV allele 1 could be distinguished from alleles 2 and 3.

SNP analysis and bioinformatics

PCR reactions included a mixture of templates reflecting the different alleles in DNA samples from heterozygous diploid and tetraploid genotypes. Trace files from directly sequenced PCR products were analysed for secondary peaks, indicative for SNPs, with the Vector NTI software package from Invitrogen. Homology searches were performed at the NCBI webpage (http://www.ncbi.nlm.nih. gov/), the TGI webpage (http://compbio.dfci.harvard.edu/ tgi/cgi-bin/tgi/Blast/index.cgi), the SGN webpage (http:// sgn.cornell.edu/), and the PGSC webpage (restricted access; http://bacregistry.potatogenome.net/pgscreg/main.py). To study possible effects of amino acid changes on functionality of the protein the programs SIFT (Sorting Intolerant From Tolerant, see http://sift.jcvi.org/ [Ng and Henikoff 2006]) and PolyPhen (Polymorphism Phenotyping, see http://coot. embl.de/PolyPhen/) were used. Classification of the nonLTR retrotransposon sequence in Zep allele 1 was performed at http://www.girinst.org/RTphylogeny/RTclass 1 .

Genetic mapping and QTL analysis in the diploid $\mathrm{C} \times \mathrm{E}$ population

A $\mathrm{C} \times \mathrm{E}$ genetic map using $94 \mathrm{C} \times \mathrm{E}$ progeny was made based on an earlier version of the map (Celis-Gamboa 2002) with additional SNP markers (Anithakumari et al. 2010) using mapping software Joinmap $4.0^{\circledR}$ (Van Ooijen 2006). QTL analysis of quantitative data was performed using the software package MapQTL ${ }^{\circledR}$ Version 5.0 (Van Ooijen 2004).

\section{Cloning of Zep promoter sequence}

The promoter sequence of Zep allele 1 was obtained by Genome Walking using the Universal GenomeWalker kit (Clontech) and the BD Advantage 2 PCR Enzyme System (BD Biosciences). DNA from diploid genotype R5 (homozygous for Zep allele 1) was used as template. Four libraries were made using DraI, EcoRV, StuI and ScaI enzymes. The 
first PCR was performed with primer AP1 and gene-specific primer AWZEPGW1 ( $5^{\prime}$-TTCTGTGGAACCTTCAAATC ACCGTTA- $3^{\prime}$ ). The nested PCR was performed with primer AP2 and gene-specific primer AWZEPGW2 (5'-GCCCATT TTCCAAGCTCCTACAAGGTA- ${ }^{\prime}$ ). The DraI- and StuIlibraries yielded a 1.1 and $1.8-\mathrm{kb}$ PCR fragment, respectively. The $1.8-\mathrm{kb}$ PCR fragment of the StuI library was sequenced, and proved to contain a $\mathrm{DraI}$ restriction site at the expected position.

\section{Cloning intron 1 of Zep allele 1}

To obtain the intron 1 sequence of Zep allele 1 primers AWZEP25 (5'-CTGGCTGCATCACTGGTCAAAG- $\left.3^{\prime}\right)$ and AWZEP20 ( $5^{\prime}$-TCATTCATAATTGTATCCTCCC- $\left.3^{\prime}\right)$ were used. The Expand High Fidelity PCR System (Roche Applied Science) was used to obtain the 4.7-kb PCR fragment. This fragment was cloned into pGEM-Teasy (Promega). Plasmid DNA was isolated using the Promega Wizard Plus minipreps DNA Purification system. DNA from three independent colonies was first sequenced using the T7, AWZEP25 and AWZEP20 primers, and subsequently with primers designed on the obtained sequences.

\section{Measurement of carotenoids}

From 94 progeny of the diploid $\mathrm{C} \times \mathrm{E}$ population carotenoids were extracted and analysed by HPLC with photodiode array (PDA) detection, according to the protocol described by Bino et al. (2005). In short, $0.5 \mathrm{~g}$ FW of ground and frozen tuber material was extracted with methanol/chloroform/1 M NaCl in $50 \mathrm{mM}$ Tris ( $\mathrm{pH}$ 7.4) in a ratio of 2.5:2:2.5 (v:v:v) containing $0.1 \%$ butylated hydroxytoluene (BHT). After centrifugation, the samples were re-extracted with $1 \mathrm{ml}$ chloroform $(+\mathrm{BHT})$. The chloroform fractions were combined, dried under a flow of $\mathrm{N}_{2}$ gas and taken up in ethyl acetate containing $0.1 \%$ BHT. Carotenoids present in the extracts were separated by HPLC using an YMC-Pack reverse-phase C30 column and analysed by PDA detection with wavelength range set from 240 to $700 \mathrm{~nm}$. Eluting compounds were identified based on their absorbance spectra and co-elution with commercially available authentic standards (neoxanthin, violaxanthin, antheraxanthin, lutein, zeaxanthin, $\beta$-cryptoxanthin, $\varepsilon$-carotene, $\alpha$-carotene, $\beta$-carotene, $\zeta$-carotene, $\delta$-carotene, prolycopene and all-trans lycopene. Limit of detection was about $5 \mu \mathrm{g}$ per $100 \mathrm{~g} \mathrm{FW}$ and technical variation (6 independent extractions and analyses of the same tuber powder) was less than $8 \%$.

In addition to the measurement of individual carotenoids yellowness of the tuber flesh of the $94 \mathrm{C} \times \mathrm{E}$ progeny was determined by spectrophotometry. The same carotenoid extraction used for HPLC analysis was measured with a
Perkin Elmer UV/MS Spectrometer Lambda 10. The peak area from 380 to $515 \mathrm{~nm}$ was determined with the UV WinLab software from Perkin Elmer using the 525$580 \mathrm{~nm}$ measurement as baseline. The peak area in the yellow spectrum is referred to as absorbance between 380 and $515 \mathrm{~nm}$.

\section{Quantitative RT-PCR}

Total RNA of 23 selected genotypes of the $\mathrm{C} \times \mathrm{E}$ population was isolated from mature tubers as described by Bachem et al. (1998). mRNA was purified using the RNeasy mini kit (Qiagen) and reverse transcribed using the iScript cDNA synthesis kit from Bio-Rad. Relative expression level of the Zep locus was determined by realtime quantitative reverse transcriptase PCR (qRT-PCR) on an iQ detection system (Bio-Rad) according to the Bio-rad iQ SYBR Green Supermix protocol. The primer sequences used for the analysis were StZEP_RT_F (5'-AAGTGCCGAGTCAGGAAGCC- $3^{\prime}$ ) from exon 7 and StZEP_RT_R ( $5^{\prime}$-CAAGTCCGACGCCAAGATAAGC-3') from exon 8. Potato elongation factor $1-\alpha(E F l \alpha)$ primers were used for relative quantification (Nicot et al. 2005). Relative quantification of the target RNA expression level was performed using Bio-rad iQ5 analysis program.

\section{Accession numbers}

Sequence data from this article can be found in the EMBL/ GenBank data libraries under accession numbers HM013963 (potato Chy2 genomic sequence), HM013964 (potato Zep allele 1 genomic sequence) and HM013965 (potato Zep allele 2 genomic sequence). The potato Lcye genomic sequence is available in the Third Party Annotation Section of the DDBJ/EMBL/GenBank databases under the accession number TPA: BK007065. The sequence of the PCR fragment obtained with primers AWLCYe1 and AWLCYe2 for allele 4 is available under accession number HM011105. Accession numbers for the BAC sequences are AC216345 (tomato BAC LE_HBa-11D12), AC238165 (potato BAC RH091F11), AC238104 (RH071N14), AC23 8398 (RH196E12), AC238240 (RH132J19) and AC215383 (tomato BAC C02HBa0104A12).

\section{Results}

Allelic variation for the beta-carotene hydoxylase 2 gene (Chy2)

We started our investigation of the genetic requirements for orange potato tuber flesh by analysing whether 
orange-fleshed diploid potato genotypes contain different Chy2 alleles than white- or yellow-fleshed tetraploid cultivars. Chy 2 was observed to be an important gene involved in tuber flesh colour in two separate studies performed on diploid populations (Brown et al. 2006; Kloosterman et al. 2010). RNA expression analysis using the $44 \mathrm{~K} \mathrm{POCI}$ array (Kloosterman et al. 2008) resulted in the identification of an eQTL for yellow tuber flesh colour on potato chromosome 3 at a similar position as the Chy 2 gene. Further analysis indicated that in the diploid $\mathrm{C} \times \mathrm{E}$ population the parent C-specific allele of the Chy2 gene was correlated with yellow flesh. This allele shows higher expression than the other two alleles segregating in the $\mathrm{C} \times \mathrm{E}$ population (Kloosterman et al. 2010). Goo et al. (2009) also observed a higher expression level of Chy2 associated with yellow flesh colour in a small number of potato cultivars.

In order to study allelic variation for the Chy 2 gene in tetraploids we first determined the complete genomic sequence of the Chy 2 allele in monohaploid $(2 n=x=12)$ potato genotype 7322 , as only mRNA and EST sequences were known for the potato Chy2 gene. The obtained 2,255bp genomic sequence (Fig. 1) contains seven exons. Next, we performed direct sequencing analyses of a PCR fragment obtained with primers CHY2ex4F and Beta-R822, spanning exon 4, intron 4 and exon 5 of the Chy 2 gene (Fig. 1). We used DNA of four additional potato monoploids, 20 S. phureja and S. chacoense monoploids, and 11 diploids. From these sequences in total eight different haplotypes could be determined (Supplemental Table S1; alleles 1-7 and 11).

We observed a correlation between presence of a single haplotype-allele 3-and yellow flesh colour in a number of diploids. Heterozygosity for allele 3 is sufficient for yellow flesh colour, indicating this is a dominant allele. This observation corroborates the results of genetic analysis of the Chy2 (or Bch) gene by Brown et al. (2006). Furthermore, we observed that SNP 142C distinguished Chy 2 allele 3 from all other haplotypes. As this SNP is unique to one haplotype it is a so-called 'haplotype tag SNP' (Johnson et al. 2001), hereafter referred to as 'tag

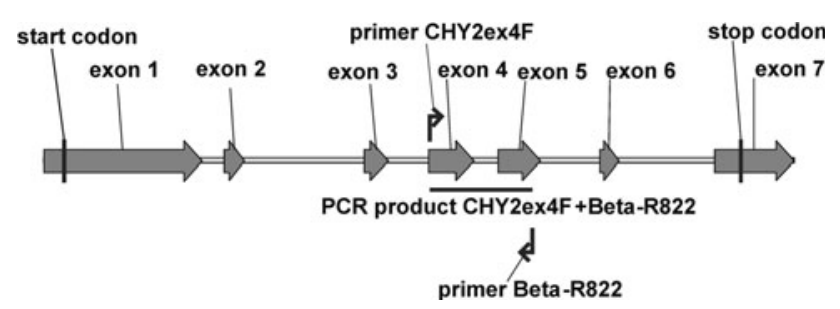

Fig. 1 Schematic representation of the genomic sequence of the potato beta-carotene hydroxylase 2 (Chy2) gene. The 2,255-bp of allele 1 of monoploid 7322 is shown. The PCR product analysed for the presence of SNPs is indicated
SNP'. Allele 3 is most probably identical to the dominant allele B described by Brown et al. (2006), because sequencing of allele 3 showed the presence of allele B-specific primer sequence YellowF1. This allele is considered to be the dominant $\mathrm{Y}$ allele at the Yellow $(Y)$ locus first postulated by Fruwirth (1912).

Next, we performed a SNP analysis on the DNA of a set of 225 tetraploid potato cultivars (D'hoop 2009). This set aims to represent the most important potato cultivars of the last 150 years in terms of acreage and/or value as progenitor, mainly from Europe, but also from the USA, Canada, and some other continents. The same PCR fragment that was analysed for the monoploids and diploids was amplified in the tetraploids. Direct sequencing was performed, which resulted in the discovery of three additional alleles (Supplemental Table S1; alleles 8, 9, 10). The dosage of SNP 142C (i.e. allele 3) was determined from the sequence trace files. Dosage of allele 3 could also be estimated by using a CAPS marker assay (Supplemental Fig. S1), in which of all Chy 2 alleles only allele 3 yielded a 163-bp fragment. The allele 3 dosage was related to the flesh colour value (Table 1). A flesh colour value of 5.5 or lower represents white flesh, whereas a flesh colour value higher than 5.5 indicates yellow flesh. As is shown in Table 1 presence or absence of Chy 2 allele 3 is correlated with flesh colour: the group of cultivars lacking allele 3 have a mean value of 5.1 (white flesh), whereas the cultivars simplex, duplex, triplex or quadruplex for allele 3 have a mean value higher than 6 (yellow flesh). The data suggest a dosage effect of allele 3 as the quadruplex genotypes have the highest mean value. However, this group consists of only two genotypes. Although there is a clear correlation between presence of Chy 2 allele 3 and yellow flesh, the intensity of the yellow flesh colour shows considerable variation within the different dosage groups, as shown in Fig. 2. This was also observed by Brown et al. (2006).

To evaluate if Chy 2 alleles other than allele 3 have a (small) influence on flesh colour the Chy 2 allele composition was determined for 199 of the 225 tetraploid potato

Table 1 Relation between the number of Chy 2 alleles and tuber flesh colour

\begin{tabular}{llll}
\hline Chy2 allele 3 dosage & $\begin{array}{l}\text { Mean tuber flesh } \\
\text { colour value }\end{array}$ & $\begin{array}{l}\text { Flesh } \\
\text { colour }\end{array}$ & $\begin{array}{l}\text { Number of } \\
\text { genotypes }\end{array}$ \\
\hline $0 \times$ (nulliplex) & 5.0 & White & 69 \\
$1 \times($ simplex $)$ & 6.3 & Yellow & 71 \\
$2 \times($ duplex $)$ & 6.5 & Yellow & 46 \\
$3 \times($ triplex $)$ & 6.6 & Yellow & 11 \\
$4 \times($ quadruplex $)$ & 7.4 & Yellow & 2 \\
\hline
\end{tabular}




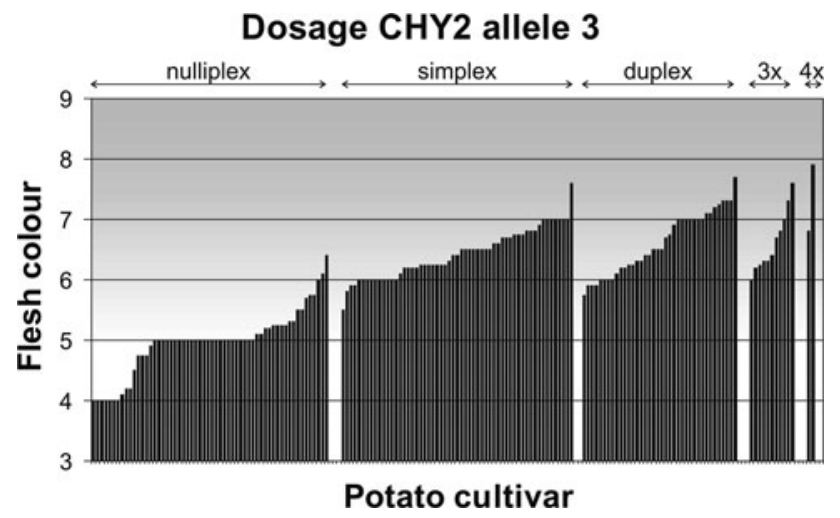

Fig. 2 Variation in flesh colour value in classes of tetraploid potato genotypes with $0 \times, 1 \times, 2 \times, 3 \times$, and $4 \times$ Chy 2 allele 3 . Flesh colour value equal to or below 5.5 is considered to correspond to white flesh, values above 5.5 are indicative of yellow flesh

genotypes by analyzing tag SNPs. Large differences in allele frequency were observed. Four major alleles were observed: alleles 5 (35\%), 3 (26\%), 1 (20\%) and $2(13 \%)$. Four minor alleles were observed: alleles $6(4 \%), 10$ $(2 \%), 8(0.8 \%)$ and $9(0.3 \%)$. Alleles 4,7 and 11 were not observed in the tetraploid $S$. tuberosum cultivars and seem to be restricted to diploid germplasm. Minor allele 6 has been present in the Solanum tuberosum gene pool for a long time, as it is observed in nine cultivars released before 1900. Minor alleles 8,9 and 10 seem to be novelties in the $S$. tuberosum gene pool, because these alleles are only present in cultivars released to the market after 1960, directly descending from backcross introgression material with late blight or cyst nematode resistance. For example, allele 10, containing an indel (1-nt deletion) in the analysed PCR fragment, is present in a number of cultivars derived from VTN 62-33-3 (1962), suggesting that this might be an $S$. vernei allele (see Kort et al. 1972).

None of the alleles $1,2,5,6,8,9$ or 10 were related to yellow flesh colour. Furthermore, none of these alleles influenced flesh colour value within the white/creamy flesh colour class, nor within the yellow flesh colour class. Thus, the variation in intensity of yellow flesh colour can not be explained by the composition of the other Chy 2 alleles in the simplex, duplex and triplex allele 3 groups.

Chy2 allele composition was determined in diploid orange-fleshed genotypes 'Papa Pura', 'Andean Sunrise', 'Yema de Huevo', IvP92-030-11 and IvP01-84-19. Although they all contained one Chy 2 allele 3, they differed in the other allele, and no novel allele absent from the tetraploid gene pool was discovered. Therefore, we concluded that other genes-possibly involved in the carotenoid biosynthetis pathway-influenced the intensity of the yellow flesh colour.
Allelic variation for the lycopene epsilon cyclase gene (Lcye)

The lycopene epsilon cyclase gene product is required for the synthesis of $\alpha$-carotene, the precursor of lutein (see Tanaka et al. 2008). Silencing of the Lcye gene resulted in a significant increase in the beta-carotenoids (Diretto et al. 2006). An increase in the level of beta-carotene and zeaxanthin is expected to result in a darker yellow flesh.

To be able to analyse allelic variation for the Lcye gene in potato we needed information on the genomic sequence of the Lcye gene. Tomato BAC LE_HBa-11D12 (from chromosome 12) contains the tomato homologue of Lcye. Using this sequence four potato BAC clones from diploid genotype RH89-039-16 containing the potato Lcye homologue were retrieved from the Potato Genome Sequencing Consortium (PGSC) database: RH091F11, RH071N14, RH196E12 and RH132J19. The 7,000-bp genomic sequence of the Lcye gene contains 11 exons (Fig. 3). Primers AWLCYe1 and AWLCYe2 were designed, which amplified a fragment spanning exon 7 to exon 9 of the Lcye genomic sequence (Fig. 3). PCR fragments from the monoploids and diploids were directly sequenced, and 5 different alleles could be observed (Supplemental Table S2). Potato BACs RH091F11 and RH071N14 contained allele 4, whereas two BACs from the homologous chromosome (RH196E12-4 and RH132J19-7) contained allele 1 of diploid genotype RH89039-16.

Two alleles (allele 2 and allele 5) contain a T at SNP position 545. This nucleotide causes a change of amino acid 401 of the Lcye protein from $\mathrm{S}$ (serine) to $\mathrm{F}$ (phenylalanine). To analyse the effect of this amino acid change we consulted two software programs: SIFT and PolyPhen. According to the SIFT program an F at position 401 is not tolerated, and according to the PolyPhen program it is possibly damaging. Diploid genotype $\mathrm{C}$ contains Lcye alleles 2 and 3, while genotype E contains Lcye alleles 1 and 2. Thus, $\mathrm{C}$ and $\mathrm{E}$ have Lcye allele 2 in common. Therefore, $25 \%$ of the progeny of a cross between these

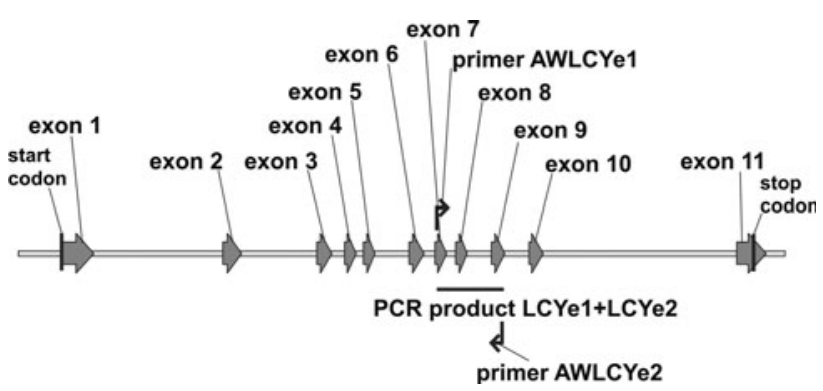

Fig. 3 Schematic representation of the genomic sequence of the potato lycopene epsilon cyclase (Lcye) gene. A 7,000-bp sequence from BAC RH091F11 from diploid genotype RH89-039-16 is shown. The PCR product analysed for the presence of SNPs is indicated 
genotypes is expected to be homozygous for allele 2 . Some of the progeny of the $\mathrm{C} \times \mathrm{E}$ cross have a much higher flesh colour value than the yellow parent $C$, i.e. some have orange flesh. To investigate whether homozygosity of Lcye allele 2 leads to a difference in flesh colour $94 \mathrm{C} \times \mathrm{E}$ progeny plants were analysed for their Lcye allele composition by CAPS marker assays. Data were used to localize the Lcye gene on the $\mathrm{C} \times \mathrm{E}$ linkage map. As expected, Lcye mapped to a position on chromosome 12 close to the STM2028 microsatellite marker and the SUS4 gene at the Southern distal end of the chromosome.

Dosage of Lcye allele 2 and dosage of Chy 2 allele 3 were plotted against flesh colour value (Fig. 4). This figure shows a strong correlation between presence of Chy 2 allele 3 and a high value for flesh colour, whereas dosage of Lcye allele 2 does not seem to have an influence on flesh colour. This suggests that a different gene than Lcye must have an influence on intensity of yellow flesh colour.

Allelic variation for the zeaxanthin epoxidase gene (Zep)

Another candidate gene for orange tuber flesh in potato is the Zep gene. Zep is involved in the conversion of zeaxanthin into antheraxanthin, and in the conversion of antheraxanthin into violaxanthin (Tanaka et al. 2008). Silencing of the Zep gene in potato resulted in transformants with higher zeaxanthin levels, and increased total carotenoid contents (Römer et al. 2002). Similarly, Morris et al. (2004) observed an inversed trend between the level of Zep transcript and tuber carotenoid content in a range of potato germplasm.

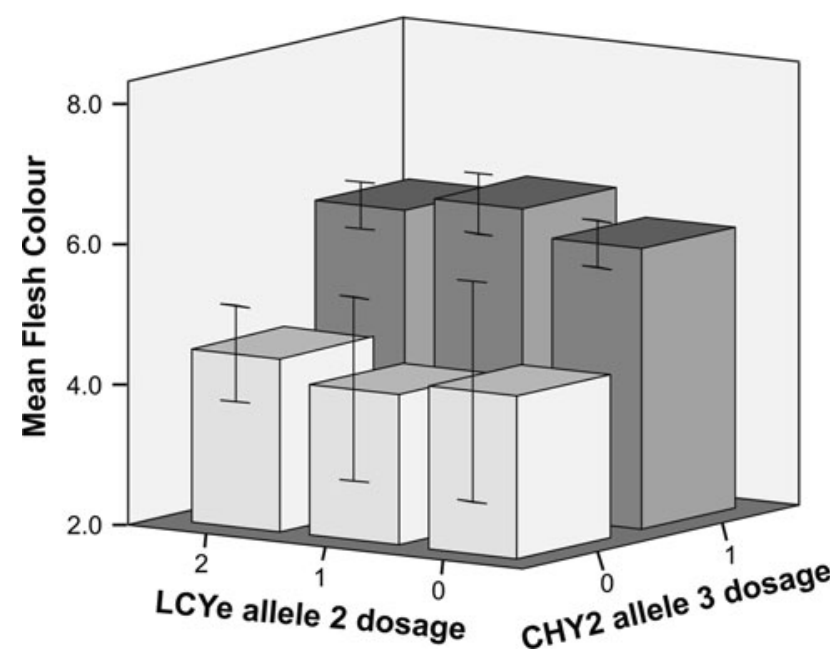

Fig. 4 Relation between Chy2 allele 3 dosage, Lcye allele 2 dosage, and phenotypic value of tuber flesh colour in the diploid $\mathrm{C} \times \mathrm{E}$ mapping population. Error bars $\pm 2 \mathrm{SE}$
A genomic sequence of the tomato Zep gene was found

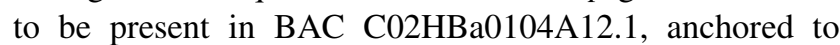
tomato chromosome 2 (Supplemental Fig. S2), which is in agreement with the map position of the pepper (Capsicum) Zep gene on chromosome 2 (Thorup et al. 2000). Using the tomato BAC sequence and potato Zep cDNA sequence DQ206629 primers were designed allowing amplification and sequencing of the complete potato Zep gene (Fig. 5). Using primer combination AWZEP9 + AWZEP10 five different alleles could be distinguished in the monoploid and diploid $S$. tuberosum genotypes (Supplemental Table S3, alleles 1-5). The AWZEP9 + AWZEP10 PCR product, spanning exon 3 to exon 5 , showed the presence of a relatively large indel in intron 4. In Zep allele 1 a sequence of $49 \mathrm{bp}$ is absent, which is present in alleles 2, 3, 4 and 5 . Therefore, Zep allele 1 could be distinguished from the other alleles by gel electrophoresis. The AWZEP9 + AWZEP10 PCR product of allele 1 is 535 bp long, whereas this PCR product is 584 bp for the other alleles (Supplemental Fig. S3b).

\section{Recessive inheritance of orange tuber flesh}

Zep allele composition was determined in diploid orangefleshed genotypes 'Papa Pura', 'Andean Sunrise', 'Yema de Huevo', IvP92-030-11 and IvP01-84-19. All five genotypes proved to be homozygous for Zep allele 1. As these five genotypes are not closely related to each other this suggests the involvement of Zep allele 1 in the orange flesh phenotype.

Genetic evidence for the involvement of Zep allele 1 in orange flesh colour was obtained from cosegregation in the diploid IvP92-030 population (progeny of the cross between diploids G254 and SUH2293). This population was analysed for both Chy2 and Zep allele compositions (Supplemental Fig. S3). Parent G254 contained CHY2 alleles 2 and 6, while parent SUH2293 contained Chy2 alleles 3 and 5. Progeny with allele combinations $2+3$, $2+5,3+6$ and $5+6$ were observed (Supplemental Fig. S3a). Both parents G254 and SUH2293 contained Zep alleles 1 and 2. Progeny with allele combinations $1+1$, $1+2$ and $2+2$ were obtained in numbers compatible with the expected 1:2:1 ratio (Supplemental Fig. S3b). Only progeny plants IvP92-030-9 and IvP92-030-11, containing Chy 2 allele 3 and homozygous for Zep allele 1, showed the orange-fleshed phenotype. This suggests a model in which presence of dominant Chy 2 allele 3 and homozygosity for recessive Zep allele 1 are required to obtain an orange-fleshed potato.

To investigate this further progeny of the $\mathrm{C} \times \mathrm{E}$ cross was analysed for Zep allele composition. Both $\mathrm{C}$ and $\mathrm{E}$ parents contain Zep alleles 1 and 2. A CAPS marker was 
Fig. 5 Schematic representation of the genomic sequence of the potato zeaxanthin epoxidase (Zep) gene. a 11,000-bp sequence of allele 1 , including promoter and coding region; b 6,008-bp sequence of allele 2 , including promoter and coding region

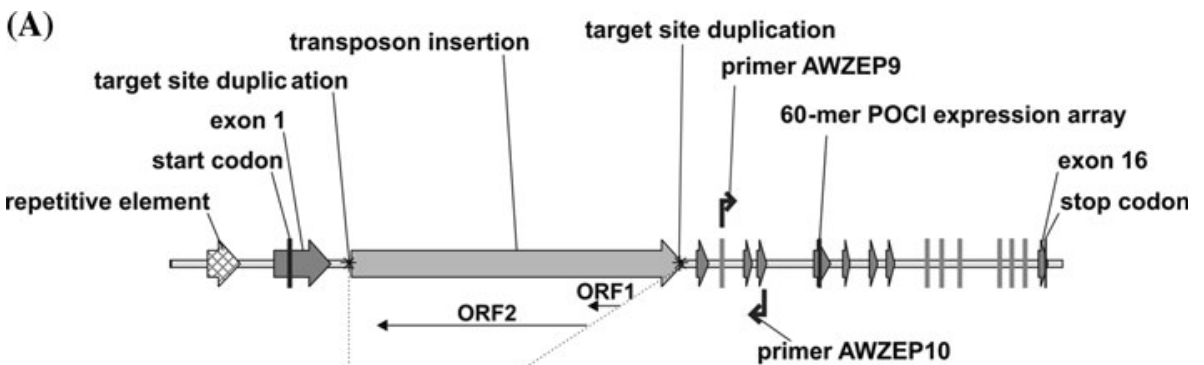

(B)

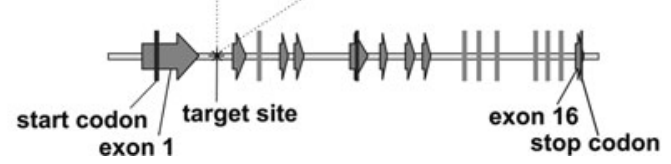

developed to easily distinguish both Zep alleles. For this, PCR product AWZEP9 + AWZEP10 was digested with the enzyme Hin6I. The PCR product of Zep allele 1 remained undigested, whereas the PCR product of allele 2 was digested into fragments of 439 and $145 \mathrm{bp}$. Ninetyfour $\mathrm{C} \times \mathrm{E}$ progeny were analysed with this CAPS marker. The Zep gene was mapped in the $\mathrm{C} \times \mathrm{E}$ population on chromosome 2 in a similar position as the one on tomato chromosome 2 (Supplemental Fig. S2). Dosage of Zep allele 1 and dosage of Chy 2 allele 3 were related to flesh colour value (Fig. 6). This figure shows that homozygosity of Zep allele 1 in combination with presence of Chy 2 allele 3 results in a significantly higher mean flesh colour value. A QTL analysis for absorbance in the yellow spectrum in the $\mathrm{C} \times \mathrm{E}$ population resulted in a highly significant QTL on chromosome 2, on the same position as the Zep gene (B. Kloosterman, pers.comm.).

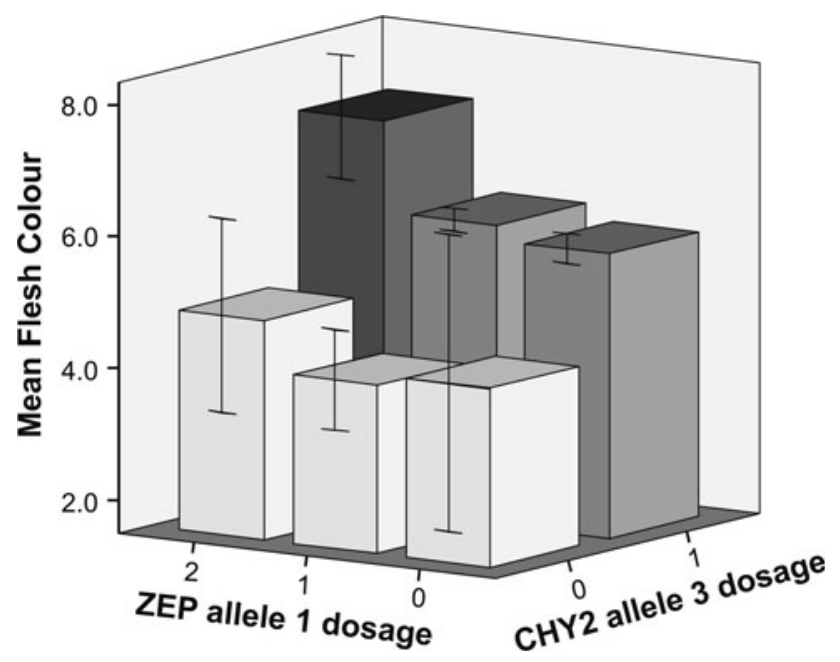

Fig. 6 Relation between Chy2 allele 3 dosage, Zep allele 1 dosage, and flesh colour value in the diploid $\mathrm{C} \times \mathrm{E}$ population. Error bars $\pm 2 \mathrm{SE}$
Role of Zep allele 1 on zeaxanthin levels

For $88 \mathrm{C} \times \mathrm{E}$ progeny the amounts of individual carotenoids were determined. A small number of progeny (10 genotypes) proved to contain relatively high levels of zeaxanthin $(>250 \mu \mathrm{g}$ per $100 \mathrm{~g}$ fresh weight). These progeny invariably contained Chy 2 allele 3 and were homozygous for Zep allele 1. In Fig. 7 the relation between zeaxanthin content and absorbance in the yellow spectrum is displayed for four classes of genotypes. Y or y represent the dominant or recessive Chy 2 allele, respectively, and $\mathrm{Z}$ or $\mathrm{z}$ represent the dominant or recessive Zep allele. $\mathrm{Y}$ is Chy2 allele 3, and $\mathrm{z}$ is Zep allele 1. This figure shows that zeaxanthin only accumulates in considerable amounts in genotypes homozygous for Zep allele 1 (zz, filled symbols). When dominant Chy 2 allele 3 is present (Yyzz) the zeaxanthin level is higher than when this allele is absent (yyzz). These results

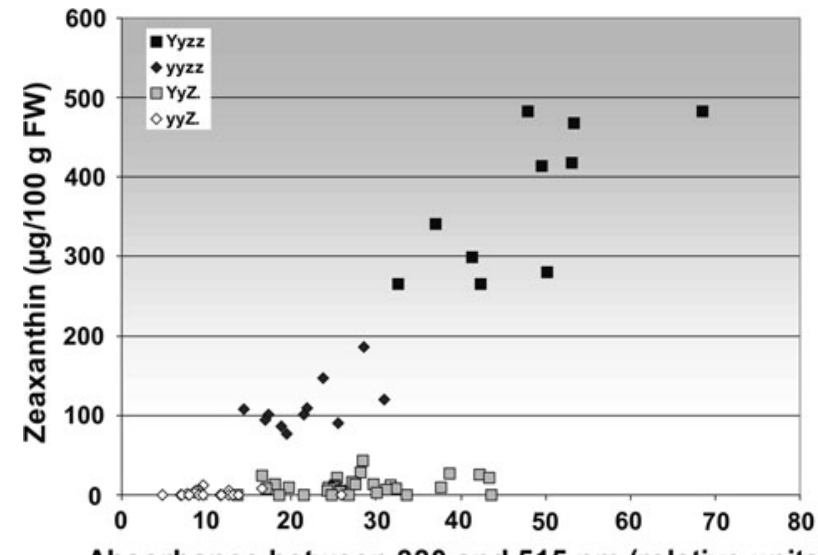

Absorbance between 380 and $515 \mathrm{~nm}$ (relative units)

Fig. 7 Relation between zeaxanthin content and absorbance in the yellow spectrum in the diploid $\mathrm{C} \times \mathrm{E}$ population. Zeaxanthin content in $\mu \mathrm{g} / 100 \mathrm{~g}$ fresh weight. Four genotypic classes are indicated, with Y/y respresenting Chy 2 alleles, and $\mathrm{Z} / \mathrm{z}$ representing Zep alleles. $\mathrm{Y}$ is dominant Chy2 allele 3; $\mathrm{z}$ is recessive Zep allele 1 
suggest that orange flesh colour indicates the presence of a zeaxanthin level of more than $250 \mu \mathrm{g} / 100 \mathrm{~g}$ fresh weight tuber.

\section{ZEP allele 1 is expressed at a low level}

Expression analysis using the $44 \mathrm{k}$ POCI array indicated that tuber RNA from parents $\mathrm{C}$ and $\mathrm{E}$ showed a similar level of hybridization to the Zep-derived 60-mer oligo (B. Kloosterman, pers. comm.). Both parents are heterozygous for Zep, containing alleles 1 and 2. Tuber RNA from $\mathrm{C} \times \mathrm{E}$ progeny homozygous for Zep allele 2 showed a higher level of hybridization with the Zep oligo than both parents, whereas tuber RNA from $\mathrm{C} \times \mathrm{E}$ progeny homozygous for Zep allele 1 showed a lower level of hybridization than both parents. This may reflect a difference in homology of the Zep alleles with the oligo. It was found that the 60-mer oligo on the POCI array (Kloosterman et al. 2008) is identical to a sequence in exon 6 of Zep allele 1, while there is one mismatch with the sequence in Zep allele 2. If the mismatch would result in a lower level of hybridization it would be expected that RNA from progeny homozygous for Zep allele 2 would show a lower level of hybridization. However, the opposite was observed. Therefore, the array results suggest that Zep allele 2 is expressed at a higher level than Zep allele 1. This was confirmed by quantitative RT-PCR (Fig. 8): diploid $\mathrm{C} \times \mathrm{E}$ progeny homozygous for ZEP allele 1 showed a significantly lower level of expression than $\mathrm{C} \times \mathrm{E}$ progeny homozygous for ZEP allele 2. Heterozygous progeny displayed an intermediate level of expression. A similar observation was made by Morris et al. (2004) who found that high carotenoid-accumulating diploid S. phureja genotype

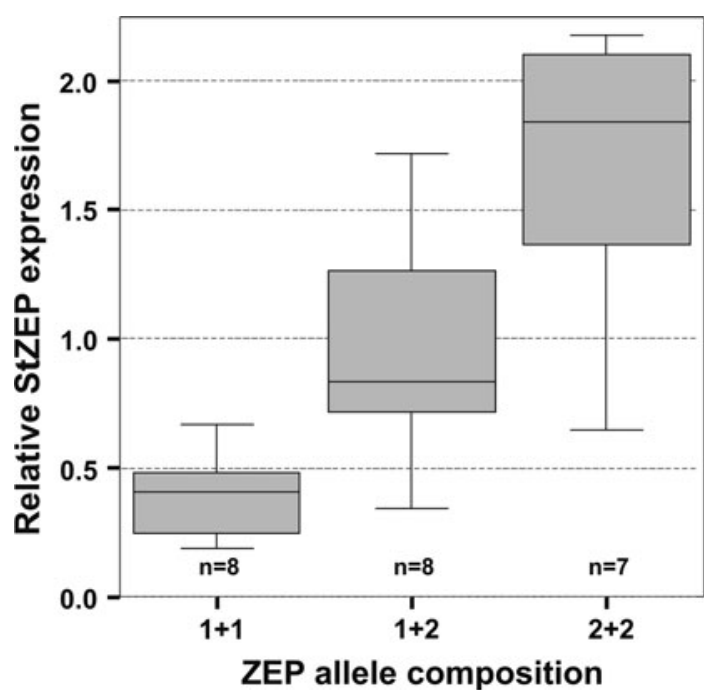

Fig. 8 Quantitative RT-PCR of Zep alleles. Relative expression level of the Zep gene for $\mathrm{C} \times \mathrm{E}$ progeny homozygous for allele 1 , heterozygous (allele $1+$ allele 2), or homozygous for allele 2. Zep allele 1 results in a lower expression level than Zep allele 2
DB375\1 (later renamed cultivar 'Inca Dawn') showed low expression of the Zep gene. They observed an inverse relationship between zeaxanthin transcript level and total carotenoid content in a range of potato germplasm.

To investigate the reason for the lower expression level of Zep allele $1 \mathrm{a} 1.8-\mathrm{kb}$ fragment containing the promoter of this allele was obtained by Genome Walking and was sequenced. A BLASTN analysis revealed that the 5'part of this sequence contained a repetitive element (present on several chromosomes of $S$. tuberosum and S. lycopersicum). An analysis of cis-regulatory elements showed that the ZEP promoter contains light-regulated, phytochromeregulated, and water stress-regulated boxes, as well as hypo-osmolarity-responsive and sugar-repression elements. Subsequently, this sequence was compared with the promoter sequence of Zep allele 2 (as present in monoploid M133), see Supplemental Fig. S4. Although a number of SNPs was observed, no obvious differences were found that could explain the different expression levels.

Next, the complete genomic sequence, including all exons and introns, was determined for both Zep alleles 1 and 2 (Fig. 5 and Supplemental Fig. S4). The exon sequences were translated into protein sequences and aligned to each other (Supplemental Fig. S5). Although a number of amino acid changes were observed, especially in the first exon, no obvious amino acid change was found predicting a non-functioning enzyme according to SIFT. Alignment of the deduced amino acid sequences of Zep alleles 1 and 2 with Zep protein sequences of other Solanaceous species (Supplemental Fig. S6) indicated that the differences in amino acids between Zep alleles 1 and 2 mostly occurred in the least conserved regions.

However, we observed a large difference in size in the first intron. Intron 1 in Zep allele 2 is 389 bp in size, comparable with the 438-bp intron 1 of the tomato Zep genomic sequence. In contrast, the size of intron 1 in Zep allele 1 is 4,509 bp. By comparing the sequences of the first intron of Zep alleles 1 and 2 we observed that a 4,102bp non-LTR retrotransposon-like sequence had integrated in intron 1 of allele 1 , causing a target site duplication of $18 \mathrm{bp}$. Analysis of this sequence showed the presence of two open reading frames (ORFs) in the DNA strand antisense relative to the promoter (Fig. 5a). The first ORF contains an endonuclease/ exonuclease domain. The second ORF contains a non-LTR retrotransposon reverse transcriptase domain. Alignment of the reverse transcriptase domain of the retrotransposon in intron 1 in Zep allele 1 (ZEPphur) with the domains of LINE-1 like retrotransposons from other species is shown in Supplemental Fig. S7. Analysis of the protein sequence of ORF2 at the non-LTR retrotransposon classification webpage (Kapitonov et al. 2009) revealed that the retrotransposon in Zep allele 1 belongs to the RTE clade, and is closely related 
to the RTE1_ZM retrotransposon from Zea mays (Obukhanych and Jurka 2007). A BLASTN search of this retrotransposon sequence using the available potato genomic sequences at the PGSC webpage revealed homologous sequences on all 12 potato chromosomes, except chromosome 7. A similar search at the NCBI webpage using the high throughput genomic sequences (HTGS) database showed the presence of homologous retrotransposon sequences in several Solanaceous species, e.g. Solanum, Nicotiana, Petunia and Capsicum species. A BLASTN search using EST databases revealed that transcription of sequences homologous to the ZEPphur retrotransposon occurs.

Occurrence of ZEP allele 1 in the tetraploid potato gene pool

To determine the frequency of Zep allele 1 in the tetraploid potato gene pool PCR with primers AWZEP9 + AWZEP10 was performed using DNA from a set of 221 tetraploid potato cultivars (D'hoop et al. 2008) and some additional cultivars. From 230 genotypes that yielded a PCR product only 5 contained Zep allele 1, all in simplex. These were genotypes Black 1256, Prevalent (descendent from Black 1256), Producent (descendent from Prevalent), Lady Claire and Pallas (both descendents from S. phureja PHUR 71-464-7). This indicates that Zep allele 1 is a rare allele in the tetraploid potato gene pool (frequency $0.5 \%$ ).

Zep allele composition was determined in 111 tetraploid potato genotypes not containing Zep allele 1, by sequencing the AWZEP9 + AWZEP10 PCR product. Four additional alleles were observed besides the alleles present in the monoploid and diploid genotypes (Supplemental Table S3). Alleles 2 (36\%), 3 (25\%), 4 (14\%) and 5 (20\%) were major alleles, whereas alleles $6(0.9 \%), 7(0.5 \%), 8(1.6 \%)$ and $9(1.6 \%)$ were minor alleles. The minor alleles 6-9 are all present in tetraploid potato cultivars released after 1960. Alleles 3-9 had an intron 1 of similar size as intron 1 in allele 2. Therefore none of these alleles contained the transposon insertion present in allele 1 .

\section{Discussion}

We conclude that homozygosity for Zep allele 1 in the presence of dominant Chy 2 allele 3 is causing the orange flesh colour phenotype, due to high levels of zeaxanthin. Furthermore, we conclude that Zep allele 1 is a recessive allele. The accumulation of zeaxanthin does not seem to be caused by impaired function of the Zep protein resulting from amino acid changes, as we observed no obvious amino acid changes in allele 1 compared with allele 2 . Rather, the accumulation of zeaxanthin seems to result from a lower steady state mRNA level of Zep, as determined by qRT-PCR.

Morris et al. (2004) observed an inverse relationship between the Zep transcript level and the total tuber carotenoid content. They investigated transcript level by quantitative RT-PCR using primers designed on the basis of tomato Zep cDNA sequence Z83835. However, DNA polymorphisms between potato and tomato can easily distort such analyses. Their forward primer contains an A at position 18 instead of $\mathrm{G}$, as present in potato Zep cDNA DQ206629 and potato EST CK278242. We observed only $\mathrm{G}$ at this position in our Zep alleles, including allele 1, indicating a SNP in Zep sequences between tomato and potato close to the 3 ' end of the forward primer. This mismatch may have a considerable influence on overall level of amplification in the RT-PCR experiment. We performed qRT-PCR on a diploid population segregating for Zep alleles 1 and 2, using primers without mismatches, and observed a clear difference in expression levels between genotypes homozygous for allele 1, heterozygous (allele $1+2$ ) and homozygous for allele 2 .

A small number of SNPs was observed in the promoter sequence of allele 1 compared with the sequence of allele 2 , which may explain the difference in expression level between the two alleles. However, we think it is more plausible that the difference in expression level is caused by the large retrotransposon insertion in the first intron of allele 1 . This large insertion may cause inefficient splicing of the pre-mRNA into mature mRNA, or alternative splicing caused by cryptic splice sites. Hanson (1989) reported that efficient intron splicing in plants may be constrained by intron length. Ohmori et al. (2008) reported that integration of a transposon in intron 4 of rice gene $D L$ resulted in reduced expression of the gene. Similarly, Gazzani et al. (2003) and Michaels et al. (2003) observed that weak alleles of the Arabidopsis thaliana FLC gene showing reduced expression contained a transposon in the first functional intron. A lower expression level of the zeaxanthin epoxidase gene results in the accumulation of zeaxanthin, at the expense of antheraxanthin, violaxanthin and neoxanthin (Tanaka et al. 2008). As zeaxanthin is relatively orange coloured (depending on concentration and milieu), while antheraxanthin, violaxanthin and neoxanthin are (light) yellow, this explains the orange flesh phenotype of the potato genotypes homozygous for Zep allele 1 (and containing Chy2 allele 3).

Potato genotypes homozygous for Zep allele 1 do not show the wilty phenotype as observed in Arabidopsis, Nicotiana plumbaginifolia and tomato Zep mutants (Duckham et al. 1991; Galpaz et al. 2008; Marin et al. 1996), in which synthesis of plant hormone abscisic acid (ABA), a downstream metabolite of the carotenoid pathway, is compromised. Therefore, we conclude that the 
reduced expression of Zep allele 1 does not result in complete absence of ABA.

Römer et al. (2002) achieved increased zeaxanthin levels in potato tubers by genetic engineering. However, consumer acceptance of GMO cultivars is very low. Use of the natural variant Zep allele 1 allows classical breeding for orangefleshed potato. Zep allele 1 probably is an S. phureja Zep allele, as it is almost absent in the $S$. tuberosum gene pool, and only present in a few tetraploid potato genotypes with S. phureja in their ancestry. This means that breeding of a tetraploid potato cultivar with orange tuber flesh (with high zeaxanthin content) is a challenging task.

Acknowledgments We wish to thank Dr. Richard Veilleux for kindly sending us DNA of 20 monoploid $S$. phureja/S. chacoense monoploids, Dr. Enrique Ritter for providing us with small tubers of S. phureja 'Yema de Huevo', and Agrico Research B.V. for sending us tubers of 'Papa Pura' and 'Andean Sunrise'. We thank Dr. Ric de Vos of PRI, Wageningen, for the carotenoid analysis. We thank STW for financial support of A.M.A. Wolters and J.G.A.M.L. Uitdewilligen (grant 07926), and the EU-SOL project (PL 016214-2 EU-SOL) for financial support of B.A. Kloosterman.

Open Access This article is distributed under the terms of the Creative Commons Attribution Noncommercial License which permits any noncommercial use, distribution, and reproduction in any medium, provided the original author(s) and source are credited.

\section{References}

Andre CM, Oufir M, Guignard C, Hoffmann L, Hausman JF, Evers D, Larondelle Y (2007) Antioxidant profiling of native Andean potato tubers (Solanum tuberosum L.) reveals cultivars with high levels of $\beta$-carotene, $\alpha$-tocopherol, chlorogenic acid, and petanin. J Agric Food Chem 55:10839-10849

Anithakumari AM, Tang J, van Eck HJ, Visser RGF, Leunissen JAM, Vosman B, van der Linden CG (2010) A pipeline for high throughput detection and mapping of SNPs from EST databases. Mol Breeding 26:65-75

Bachem CWB, Oomen RJFJ, Visser RGF (1998) Transcript imaging with cDNA-AFLP: a step-by-step protocol. Plant Mol Biol Rep 16:157-173

Binding H, Nehls R, Schieder O, Sopory SK, Wenzel G (1978) Regeneration of mesophyll protoplasts isolated from dihaploid clones of Solanum tuberosum. Physiol Plant 43:52-54

Bino RJ, de Vos CHR, Lieberman M, Hall RD, Bovy A, Jonker HH, Tikunov Y, Lommen A, Moco S, Levin I (2005) The lighthyperresponsive high pigment- $2^{\mathrm{dg}}$ mutation of tomato: alterations in the fruit metabolome. New Phytol 166:427-438

Bonierbale MW, Plaisted RL, Tanksley SD (1988) RFLP maps based on a common set of clones reveal modes of chromosomal evolution in potato and tomato. Genetics 120:1095-1103

Bradshaw JE, Ramsay G (2005) Utilisation of the commonwealth potato collection in potato breeding. Euphytica 146:9-19

Breithaupt DE, Bamedi A (2002) Carotenoids and carotenoid esters in potatoes (Solanum tuberosum L.): new insights into an ancient vegetable. J Agric Food Chem 50:7171-7181

Brown CR (2008) Breeding for phytonutrient enhancement of potato. Am J Pot Res 85:298-307
Brown CR, Edwards CG, Yang CP, Dean BB (1993) Orange flesh trait in potato: Inheritance and carotenoid content. $\mathrm{J}$ Amer Soc Hort Sci 118:145-150

Brown CR, Kim TS, Ganga Z, Haynes K, De Jong D, Jahn M, Paran I, De Jong W (2006) Segregation of total carotenoid in high level potato germplasm and its relationship to beta-carotene hydroxylase polymorphism. Am J Potato Res 83:365-372

Brown CR, Culley D, Bonierbale M, Amorós W (2007) Anthocyanin, carotenoid content, and antioxidant values in native South American potato cultivars. HortScience 42:1733-1736

Burgos G, Salas E, Amoros W, Auqui M, Muñoa L, Kimura M, Bonierbale M (2009) Total and individual carotenoid profiles in Solanum phureja of cultivated potatoes: I. Concentrations and relationships as determined by spectrophotometry and HPLC. J Food Compos Anal 22:503-508

Celis-Gamboa BC (2002) Life cycle of the potato (Solanum tuberosum L.): from crop physiology to genetics. Dissertation, Wageningen University, Wageningen, The Netherlands

D'hoop BB (2009) Association mapping in tetraploid potato. Dissertation, Wageningen University, Wageningen, The Netherlands

D'hoop BB, Paulo MJ, Mank RA, van Eck HJ, van Eeuwijk FA (2008) Association mapping of quality traits in potato (Solanum tuberosum L.). Euphytica 161:47-60

De Vries SE, Ferwerda MA, Loonen AEHM, Pijnacker LP, Feenstra WJ (1987) Chromosomes in somatic hybrids between Nicotiana plumbaginifolia and a monoploid potato. Theor Appl Genet 75:170-176

De Vries-Uijtewaal E, Gilissen LJW, Flipse E, Sree Ramulu K, Stiekema WJ, de Groot B (1989) Fate of introduced genetic markers in transformed root clones and regenerated plants of monohaploid and diploid potato genotypes. Theor Appl Genet 78:185-193

Diretto G, Tavazza R, Welsch R, Pizzichini D, Mourgues V, Beyer P, Giuliano G (2006) Metabolic engineering of potato tuber carotenoids through tuber-specific silencing of lycopene epsilon cyclase. BMC Plant Biol 6:13

Duckham SC, Linforth RST, Taylor IB (1991) Abscisic-acid-deficient mutants at the aba gene locus of Arabidopsis thaliana are impaired in the epoxidation of zeaxanthin. Plant Cell Environ 14:601-606

Fruwirth C (1912) Zur Züchtung der Kartoffel. Deutsche Landwirtschaftliche Presse 39(551-552):565-567

Galpaz N, Wang Q, Menda N, Zamir D, Hirschberg J (2008) Abscisic acid deficiency in the tomato mutant high-pigment 3 leading to increased plastid number and higher fruit lycopene content. Plant J 53:717-730

Gazzani S, Gendall AR, Lister C, Dean C (2003) Analysis of the molecular basis of flowering time variation in Arabidopsis accessions. Plant Physiol 132:1107-1114

Goo YM, Kim TW, Ha SH, Back KW, Bae JM, Shin YW, Lee CH, Ahn MJ, Lee SW (2009) Expression profiles of genes involved in the carotenoid biosynthetic pathway in yellow-fleshed potato cultivars (Solanum tuberosum L.) from South Korea. J Plant Biol 52:49-55

Handelman GJ, Dratz EA, Reay CC, van Kuijk FJGM (1988) Carotenoids in the human macula and whole retina. Invest Ophthalmol Vis Sci 29:850-855

Hanneman RE Jr, Peloquin SJ (1967) Crossability of 24-chromosome potato hybrids with 48-chromosome cultivars. Eur Potato J 10:62-73

Hanson MR (1989) Tracking down plant genes: paths, patterns and footprints. Plant Cell 1:169-172

Hoogkamp TJH, van den Ende RGT, Jacobsen E, Visser RGF (2000) Development of amylose-free ( $\mathrm{amf}$ ) monoploid potatoes as new basic material for mutation breeding in vitro. Potato Res 43: 179-189 
Hovenkamp-Hermelink JHM, Jacobsen E, Pijnacker LP, de Vries JN, Witholt B, Feenstra WJ (1988) Cytological studies on adventitious shoots and minitubers of a monoploid potato clone. Euphytica 39:213-219

Iwanzik W, Tevini M, Stute R, Hilbert R (1983) Caotenoidgehalt und-zusammensetzung verschiedener deutscher Kartoffelsorten und deren Bedeutung für die Fleischfarbe der Knolle. Potato Res 26:149-162

Jacobs JME, van Eck HJ, Arens P, Verkerk-Bakker B, te Lintel Hekkert B, Bastiaanssen HJM, El-Kharbotly A, Pereira A, Jacobsen E, Stiekema WJ (1995) A genetic map of potato (Solanum tuberosum) integrating molecular markers, including transposons, and classical markers. Theor Appl Genet 91: 289-300

Jacobsen E (1980) Increase of diplandroid formation and seed set in $4 \mathrm{x} \times 2 \mathrm{x}$ crosses in potatoes by genetical manipulation of dihaploids and some theoretical consequences. Z Pflanzenzuecht $85: 110-121$

Jacobsen E, Hovenkamp-Hermelink JHM, Krijgsheld HT, Nijdam H, Pijnacker LP, Witholt B, Feenstra WJ (1989) Phenotypic and genotypic characterization of an amylose-free starch mutant of the potato. Euphytica 44:43-48

Johnson GCL, Esposito L, Baratt BJ, Smith AN, Heward J, Di Genova G, Ueda H, Cordell HJ, Eaves IA, Dudbridge F, Twells RCJ, Payne F, Hughes W, Nutland S, Stevens H, Carr P, Tuomilehto-Wolf E, Tuomilehto J, Gough SCL, Clayton DG, Todd JA (2001) Haplotype tagging for the identification of common disease genes. Nat Genet 29:233-237

Kapitonov VV, Tempel S, Jurka J (2009) Simple and fast classification of non-LTR retrotransposons based on phylogeny of their RT domain protein sequences. Gene 448:207-213

Kloosterman B, De Koeyer D, Griffiths R, Flinn B, Steuernagel B, Scholz U, Sonnewald S, Sonnewald U, Bryan GJ, Prat S, Bánfalvi Z, Hammond JP, Geigenberger P, Nielsen KL, Visser RGF, Bachem CWB (2008) Genes driving potato tuber initiation and growth: identification based on transcriptional changes using the POCI array. Funct Integr Genomics 8:329-340

Kloosterman B, Oortwijn M, Celis-Gamboa C, Uitdewilligen J, America T, de Vos R, Visser RGF, Bachem C (2010) From QTL to candidate gene: a genetical genomics approach using a pooling strategy for simple and complex traits in potato. BMC Genomics 11:158

Kobayashi A, Ohara-Takada A, Tsuda S, Matsuura-Endo C, Takada N, Umemura Y, Nakao T, Yoshida T, Hayashi K, Mori M (2008) Breeding of potato variety "Inca-no-hitomi" with a very high carotenoid content. Breed Sci 58:77-82

Kort J, Jaspers CP, Dijkstra DL (1972) Testing for resistance to pathotype $\mathrm{C}$ of Heterodera rostochiensis and the practical application of Solanum vernei-hybrids in the Netherlands. Ann Appl Biol 71:289-294

Krinsky NI, Mayne ST, Sies H (2004) Carotenoids in health and disease. CRC Press, New York

Lightbourn GJ, Veilleux RE (2007) Production and evaluation of somatic hybrids derived from monoploid potato. Amer J Potato Res 84:425-435

Lopez AB, Van Eck J, Conlin BJ, Paolillo DJ, O’Neill J, Li L (2008) Effect of the cauliflower Or transgene on carotenoid accumulation and chromoplast formation in transgenic potato tubers. J Exp Bot 59:213-223

Marin E, Nussaume L, Quesada A, Gonneau M, Sotta B, Hugueney P, Frey A, Marion-Poll A (1996) Molecular identification of zeaxanthin epoxidase of Nicotiana plumbaginifolia, a gene involved in abscisic acid biosynthesis and corresponding to the ABA locus of Arabidopsis thaliana. EMBO J 15:2331-2342

Michaels SD, He Y, Scortecci KC, Amasino RM (2003) Attenuation of FLOWERING LOCUS $\mathrm{C}$ activity as a mechanism for the evolution of summer-annual flowering behavior in Arabidopsis. Proc Natl Acad Sci USA 100:10102-10107

Moeller SM, Parekh N, Tinker L, Ritenbaugh C, Blodi B, Wallace RB, Mares JA (2006) Associations between intermediate agerelated macular degeneration and lutein and zeaxanthin in the carotenoids in age-related eye disease study (CAREDS). Arch Ophthalmol 124:1151-1162

Morris WL, Ducreux L, Griffiths DW, Stewart D, Davies HV, Taylor MA (2004) Carotenogenesis during tuber development and storage in potato. J Exp Bot 55:975-982

Nesterenko S, Sink KC (2003) Carotenoid profiles of potato breeding lines and selected cultivars. HortScience 38:1173-1177

$\mathrm{Ng}$ PC, Henikoff S (2006) Predicting the effects of amino acid substitutions on protein function. Annu Rev Genomics Hum Genet 7:61-80

Nicot N, Hausman JF, Hoffmann L, Evers D (2005) Housekeeping gene selection for real-time RT-PCR normalization in potato during biotic and abiotic stress. J Exp Bot 56:2907-2914

Obukhanych T, Jurka J (2007) RTE1_ZM. Repbase Rep 7:988

Ohmori Y, Abiko M, Horibata A, Hirano HY (2008) A transposon, Ping, is integrated into intron 4 of the DROOPING LEAF gene of rice, weakly reducing its expression and causing a mild drooping leaf phenotype. Plant Cell Physiol 49:176-1184

Park TH, Vleeshouwers VGAA, Kim JB, Hutten RCB, Visser RGF (2005) Dissection of foliage and tuber late blight resistance in mapping populations of potato. Euphytica 143:75-83

Ritter E, Barandalla L, López R, Ruiz de Galarreta JI (2008) Exploitation of exotic, cultivated Solanum germplasm for breeding and commercial purposes. Potato Res 51:301-311

Rogers SO, Bendich AJ (1988) Extraction of DNA from plant tissues. In: Gelvin SB, Schilperoort RA (eds) Plant molecular biology manual. Kluwer, Dordrecht, pp A6/1-A6/10

Römer S, Lübeck J, Kauder F, Steiger S, Adomat C, Sandmann G (2002) Genetic engineering of a zeaxanthin-rich potato by antisense inactivation and co-suppression of carotenoid epoxidation. Metab Eng 4:263-272

Rouppe van der Voort JNAM, van Zandvoort P, van Eck HJ, Folkertsma RT, Hutten RCB, Draaistra J, Gommers FJ, Jacobsen E, Helder J, Bakker J (1997) Use of allele specificity of comigrating AFLP markers to align genetic maps from different potato genotypes. Mol Gen Genet 255:438-447

Seddon JM, Ajani UA, Sperduto RD, Hiller R, Blair N, Burton TC, Farber MD, Gragoudas ES, Haller J, Miller DT et al (1994) Dietary carotenoids, vitamins A, C, and E, and advanced agerelated macular degeneration. Eye Disease Case-Control Study Group. JAMA 272:1413-1420

Snodderly DM (1995) Evidence for protection against age-related macular degeneration by carotenoids and antioxidant vitamins. Am J Clin Nutr 62(suppl):1448S-1461S

Sommerburg O, Keunen JEE, Bird AC, van Kuijk FJGM (1998) Fruits and vegetables that are sources for lutein and zeaxanthin: the macular pigment in human eyes. $\mathrm{Br} \mathrm{J}$ Ophthalmol 82: 907-910

Tanaka Y, Sasaki N, Ohmiya A (2008) Biosynthesis of plant pigments: anthocyanins, betalains and carotenoids. Plant $\mathrm{J}$ 54:733-749

Thorup TA, Tanyolac B, Livingstone KD, Popovsky S, Paran I, Jahn M (2000) Candidate gene analysis of organ pigmentation loci in the Solanaceae. Proc Natl Acad Sci USA 97:11192-11197

Uijtewaal BA (1987) Ploidy variability in greenhouse cultured and in vitro propagated potato (Solanum tuberosum) monohaploids $(2 \mathrm{n}=\mathrm{x}=12)$ as determined by flow cytometry. Plant Cell Rep 6:252-255

Uijtewaal BA, Huigen DJ, Hermsen JGTh (1987) Production of potato monohaploids $(2 \mathrm{n}=\mathrm{x}=12)$ through prickle pollination. Theor Appl Genet 73:751-758 
Van der Beek JG, Verkerk R, Zabel P, Lindhout P (1992) Mapping stategy for resistance genes in tomato based on RFLPs between cultivars: CF9 (resistance to Cladosporium fulvum) on chromosome 1. Theor Appl Genet 84:106-112

Van Ooijen JW (2004) MapQTL ${ }^{\circledR}$ 5. Software for the mapping of quantitative trait loci in experimental populations. Kyazma BV, Wageningen

Van Ooijen JW (2006) JoinMap ${ }^{\circledR}$ 4. Software for the calculation of genetic linkage maps in experimental populations. Kyazma BV, Wageningen
Van Os H, Andrzejewski S, Bakker E, Barrena I, Bryan GJ, Caromel B, Ghareeb B, Isidore E, de Jong W, van Koert P, Lefebvre V, Milbourne D, Ritter E, Rouppe van der Voort JNAM, RousselleBourgeois F, van Vliet J, Waugh R, Visser RGF, Bakker J, van Eck HJ (2006) Construction of a 10,000-marker ultradense genetic recombination map of potato: providing a framework for accelerated gene isolation and a genomewide physical map. Genetics 173:1075-1087 